\title{
Discourse prominence effects on 2.5-year-old children's interpretation of pronouns
}

\author{
Hyun-joo Song ${ }^{\mathrm{a}, *}$, Cynthia Fisher ${ }^{\mathrm{b}}$ \\ ${ }^{a}$ Department of Psychology, Yonsei University, 134 Shinchon-dong, Sedaemon-gu, Seoul 120-749, \\ Republic of Korea \\ ${ }^{\mathrm{b}}$ Department of Psychology, University of Illinois, 603 East Daniel Street, Champaign, IL 61820, USA \\ Received 5 June 2006; received in revised form 30 September 2006; accepted 13 November 2006
}

Available online 24 April 2007

\begin{abstract}
Three experiments examined 2.5-year-olds' sensitivity to discourse structure in pronoun interpretation. Children heard simple two-character stories illustrated by pictures on two video screens. In Experiments 1 and 2, one character in each story was established as more prominent than the other in several context sentences because it was mentioned first, appeared in subject position, was mentioned more often, and was pronominalized once. In Experiment 3, one character was singled out as more prominent only by being mentioned first and placed in subject position. In all three experiments, after hearing a pronoun subject in the final (test) sentence of each story, children looked longer at the character established as more prominent in the preceding sentences. These experiments show that 2.5 -year-olds, like older children and adults, interpret pronouns relative to a discourse representation in which referents are ranked in prominence, and that the prominence of discourse referents is influenced by some of the same factors that guide pronoun interpretation in adulthood.
\end{abstract}

(C) 2007 Elsevier B.V. All rights reserved.

Keywords: Language acquisition; Pronouns; Discourse processing; Discourse prominence; Incremental processing

\section{Introduction}

How do young children understand pronouns? Example (1), a fragment of dialogue about a basketball game, shows the ambiguity so common in conversation and narrative (Brennan, 1995:138). By itself, Joy's question contains no hint as to who he is. To understand the question, Alonza must link the ambiguous word he with someone already mentioned or otherwise made

* Corresponding author. Tel.: +82 22123 2449; fax: +82 23654354 .

E-mail address: hsong@yonsei.ac.kr (H. Song). 
known in the conversational context. How do young children cope with the ambiguity and context-dependence of language use?
Alonza: Number forty-two passes it to forty-five ...
and forty-two goes up
and it was fouled, by number thirty-five of the Wolverines. okay ...
Joy: Is he takin' a sh- foul shot?

Many previous studies of pronoun interpretation have investigated young children's sensitivity to the syntactic constraints that limit coreference within sentences. For example, children as young as 3 years of age show signs of knowing that the pronoun himself in (2) must refer to Papa Bear, while the pronoun him in (3) cannot (e.g., Avrutin, 1999; Grimshaw and Rosen, 1990, among many others). These coreference patterns are described by the principles of Chomsky's Binding Theory (Chomsky, 1981). Roughly speaking, these principles require that a reflexive (himself) must be bound to an antecedent which is structurally more prominent (higher in the syntactic structure), or equally prominent, within a structurally-defined local domain, while a pronoun (him) cannot be so bound.

$$
\begin{aligned}
& \text { Papa Bear }{ }_{i} \text { washed himself } \\
& \text { *Papa } \text { Bear }_{\mathrm{i}} \text { washed } \text { him }_{\mathrm{i}} \text {. }
\end{aligned}
$$

These syntactic constraints, of course, provide a very incomplete guide to pronoun interpretation. In (3), the binding principles tell the listener only that him cannot be coreferential with Papa Bear; other information sources must guide the search for an antecedent.

Adults use a variety of information sources to identify the referents of pronouns or other ambiguous noun phrases. These include linguistic information sources such as definiteness, animacy, gender, and number, as well as non-linguistic sources, including inferences from background knowledge, knowledge of the situation, and the goals of the discourse (e.g., Arnold et al., 2000; Clark and Haviland, 1977; Garnham, 2000; Heim, 1982; Kintsch, 1988; Tanenhaus et al., 1995).

The role of both linguistic and non-linguistic information in pronoun resolution can be seen in example (1): The semantics of the pronoun it require that it refer to an inanimate referent - the ball in the first instance, and an attempt to make a basket in the second -, while he must refer to one of the players. We can also see the utility of inference based on background knowledge in this example. For example, the rules of basketball could tell Alonza who he is in Joy's question, because only one of the players she had mentioned could be taking a foul shot at this pointnumber 42 , the player who was fouled.

In addition to the effects of background or situational knowledge, however, a great deal of research on pronoun use and interpretation has documented a tight link between the prominence or salience of various referents in the local discourse context, and whether they can felicitously be referred to with a pronoun. In (1), Joy's pronoun he refers to a player who has been mentioned more often than any other player in the local discourse, and who was twice established as subject of a sentence. As we will see below, these are features that contribute to referent prominence. Generally speaking, entities that the linguistic context has made especially prominent are more likely to be realized as pronouns by speakers, and are more easily identified as referents for pronouns by listeners, than are less prominent referents (e.g., Almor, 1999; Ariel, 2001; Fletcher, 
1984; Gundel et al., 1993; Prince, 1992, among many others). Less prominent referents tend to be invoked by more explicit linguistic forms.

Thus, a diversity of clues including grammatical constraints, world knowledge and discourse prominence can influence pronoun interpretation. The present investigation focuses on the use of the last of these by very young children: We ask whether very young children, like older children and adults, are influenced by the prominence of candidate referents in the local discourse context when seeking antecedents for pronouns.

\subsection{The place of prominence in the discourse model}

To account for the multiplicity of effects on the interpretation of referring expressions, semanticists, psychologists, and computer scientists have proposed theories of coreference processing with three fundamental properties. Similar factors are assumed to guide the choice of referring expressions in language production, and the interpretation of referring expressions in language comprehension; for ease of exposition, we will focus on the demands of comprehension.

First, researchers have proposed that each sentence is interpreted relative to a propositional representation of the current state of the discourse (e.g., Bock and Brewer, 1985; Garnham, 2000; Gordon and Hendrick, 1997, 1998; Grosz and Sidner, 1986; Heim, 1982; Johnson-Laird, 1983; Kamp and Reyle, 1993; Kintsch, 1988). This discourse or situation model includes a set of discourse referents (the entities under discussion) and the propositions predicated over those referents (their properties, and their relationships with other referents). A propositionallyencoded discourse representation readily permits the integration of linguistically-provided information with background knowledge and aspects of the situation that are relevant to the goals of the discourse. The integration of linguistically-provided with non-linguistic information sources can be seen in such phenomena as the acceptability of deictic uses of personal pronouns or definite noun phrases to designate situationally-rather than linguistically-evoked referents (e.g., Prince, 1981), or listeners' online restriction of referential options based on task demands (Chambers et al., 2002).

Second, the form of each referring expression determines how its referent will be linked into the discourse representation. For example, listeners (even 3-4-year-olds) come to different conclusions about coreference when interpreting definite versus indefinite noun phrases (the dog versus a dog; Maratsos, 1976), and assign each definite noun phrase or pronoun to a discourse entity that matches its semantic properties, including gender and number (Arnold et al., in press; Gelman and Raman, 2003).

Third, discourse referents are assumed to be ranked in prominence. This is the fundamental insight of centering theory and its theoretical kin (Ariel, 1990; Arnold et al., 2000; Brennan, 1995; Garrod and Sanford, 1994; Gordon and Hendrick, 1997, 1998; Gordon et al., 1993; Grosz and Sidner, 1986; Walker et al., 1998). Prominence in the discourse model interacts with referential form to determine coreference: Pronouns ordinarily maintain reference to entities that are already highly prominent in the discourse representation, while more specific referential forms, such as definite noun phrases or proper names, indicate a shift in attentional focus.

\subsection{The determinants of discourse prominence}

Many factors influence the prominence of referents within a semantically interpreted discourse model, for adult speakers and listeners. 
These include recent mention: Discourse-old, or given, referents are more likely than new referents to appear early in sentences, especially in subject position, and to be deaccented, pronominalized or omitted (e.g., Bates, 1976; Clancy, 1992; Fisher and Tokura, 1995; Fowler and Housum, 1987; Chafe, 1994; Clark and Haviland, 1977; MacWhinney and Bates, 1978; Marslen-Wilson et al., 1982; Prince, 1992). Passages are easier to understand when words referring to given referents are deaccented or pronominalized (e.g., Bock and Mazzella, 1983; Cloitre and Bever, 1988; Fowler and Housum, 1987). The effect of prior mention is mediated by distance: Definite noun phrases or pronouns are most easily understood if their antecedents appeared in the immediately prior clause (e.g., Clark and Sengul, 1979; Ehrlich and Rayner, 1983).

Referent prominence is also strongly influenced by grammatical subject status. Referents that have been established as sentence subjects are more likely to be invoked again in subsequent sentences than are non-subject referents, and a repeated referent is more likely to be realized as a subject pronoun if it was the grammatical subject of the previous sentence (e.g., Arnold, 1998; Brennan, 1995; Clancy, 1980; Givón, 1976; Marslen-Wilson et al., 1982; Prince, 1992). In comprehension, adults find it easier to interpret a pronoun subject as coreferential with the immediately preceding sentence's subject (or first-mentioned noun phrase, e.g., Arnold et al., 2000; Gordon et al., 1993), and comprehension is slowed if a lexical noun phrase appears in subject position where a pronoun would suffice (Gordon et al., 1993). This "repeated name penalty" for comprehension disappears if the antecedent of the repeated noun phrase was not in subject (or initial) position in the preceding sentence.

Order of mention, independent of grammatical role, also influences referent prominence. The first noun phrase in a sentence is better recalled and serves as a more potent cue for sentence recall than other noun phrases in the same sentence, even if it is not the grammatical subject (e.g., Gernsbacher and Hargreaves, 1988; MacWhinney, 1977). Readers experience a repeated name penalty for subject noun phrases with antecedents that were sentence-initial, but not subjects, in the preceding sentence (e.g., "According to Lisa, ..."; Gordon et al., 1993). The independent effect of order can be seen more clearly in languages that permit more word-order variation than English does: in Finnish, the interpretation of subject pronouns shows effects of both first mention and subject status (Järvikivi et al., 2005).

There is also some evidence that the choice of referential forms can influence referent prominence. Less specific referential forms such as pronouns or ellipsis may serve to promote or signal a referent's prominence. In narratives, speakers tend to reserve pronominal or elliptical reference for the most prominent character in the story (e.g., Clancy, 1980; Levy, 1982).

Finally, the influence of local structural factors is mediated by global factors, such as the perceived discourse topic. Referents that are central to the global purpose of the discourse or narrative are more likely to be referred to with pronouns, and more easily understood as the referents of pronouns (e.g., Brennan, 1995; Clancy, 1980; Garrod and Sanford, 1988; Grosz et al., 1983). The topic of a discourse can be established by frequency of mention or initial mention in a discourse: Definite noun phrases or pronouns are most easily understood if their antecedents were mentioned more often and/or at the beginning of the passage (e.g., Kieras, 1980; Perfetti and Goldman, 1974).

\subsection{Children's sensitivity to discourse prominence in language production}

Do young speakers and listeners, like adults, assign varying degrees of prominence to discourse referents, and use this prominence ranking when seeking a pronoun's antecedent? Do 
similar textual factors promote prominence in children's discourse representations, and in those of adults?

Most research on the development of sensitivity to the discourse context has concentrated on language production. The emphasis of this research has often been on young children's notorious incompetence in conveying information. Comparisons of younger children with older children and adults reveal considerable development in the appropriate use of pronouns or ellipsis versus more explicit referential forms. In general, younger children over-use pronouns and ellipsis, and gradually increase their usage of more informative expressions where these are needed for referential clarity (e.g., Clancy, 1992; Deutsch and Pechmann, 1982; Hickmann and Hendriks, 1999). Children also add narrative strategies to their repertoire as they learn language-specific devices for linking referents across sentences (e.g., Jisa, 2000; Karmiloff-Smith, 1981).

At the same time, comparisons of children's productions across discourse contexts show that even very young children are strongly influenced by discourse structure in their choice of referential forms.

First, children treat given and new referents differently (e.g., MacWhinney and Bates, 1978). Children as young as 4 who were learning Chinese, English, French, or German were most likely to pronominalize (or omit, depending on native language) repeated referents that had been mentioned in the immediately preceding sentence (Hickmann and Hendriks, 1999). Two-yearolds learning Korean or Inuktitut used ellipsis much less often for new referents than for those recently mentioned (Allen, 2000; Clancy, 1997). English-speaking 2-, 3-, and 4-year-olds mostly used indefinite noun phrases to introduce new referents in elicited narratives, and definite noun phrases to mention them again (Emslie and Stevenson, 1981). Children's spontaneous speech also demonstrates sensitivity to the link between given information and subject position (e.g., Allen, 2000; Clancy, 1993): Even in the speech of 2-year-olds, given referents are typically transitive subjects, and are often realized as pronouns or omitted altogether. New referents are much less likely to be omitted or pronominalized, and tend to appear in transitive object or intransitive subject position.

Second, young speakers treat subject (or perhaps sentence-initial) noun phrases as more prominent for later reference. In elicited narratives produced by 4-year-old children learning English, French, German, or Chinese, the referent of the grammatical subject of one sentence was more likely than a non-subject referent to appear as the grammatical subject of the next sentence, and these continued subjects tended to be pronominalized or omitted rather than realized as repeated lexical nouns (Hickmann and Hendriks, 1999). Similarly, Japanese-speaking 4-yearolds omitted more continued subjects than subjects whose antecedents had not been subjects in the previous sentence (Clancy, 1992).

As is the case for adults, these local structural influences on pronominalization and ellipsis are modulated by global structural or semantic factors. In spontaneous narratives, children as young as 3 more often used pronouns or ellipsis for the hero of the story than for a secondary character (e.g., Gomme and Johnson, 1997; Hickmann and Hendriks, 1999). By about 6 years of age, children can adopt a systematic thematic subject strategy in spontaneous narrative construction (Karmiloff-Smith, 1981). French-speaking 6-year-olds also reduced their use of pronouns for highly focused referents when crossing episode boundaries in a story (Hickmann et al., 1995).

Finally, the creation of a clear topic by the posing of a specific question (e.g., What did the cow $d o$ ?) strongly affected the form of answers given by children as young as 2.5 years old: Following questions that specified a character by name, children mostly used null pronouns (e.g., spilled it.); in contrast, the posing of general questions (What happened?) increased children's use of 
demonstrative pronouns (e.g., this one spilled it.) or lexical nouns (Campbell et al., 2000; Wittek and Tomasello, 2005).

In sum, children's spontaneous speech shows both differences from, and striking similarities to, the adult pattern. Although young children tend to over-use pronouns or ellipsis in their speech relative to adults, comparisons of children's speech across contexts show a surprisingly adult-like pattern of sensitivity to discourse structure. Children tend to place more prominent referents in subject position, and are likely to pronominalize or omit them. Moreover, in the young child's language production system, referent prominence is affected by some of the same local and global structural factors that influence referential forms in adult language production.

\subsection{Children's sensitivity to discourse prominence in language comprehension}

We recently asked whether 3-year-olds would recruit discourse prominence in pronoun interpretation, using a looking-preference task to assess pronoun comprehension (Song and Fisher, 2005). Children heard short stories like the one in Table 1, while they looked at pictures on two side-by-side video screens. During the final, test sentence of each story, the two characters introduced in the initial context sentences were shown, one on each screen. Half of the test sequences contained lexical noun subjects, and half contained ambiguous pronoun subjects. The pronoun in the test sentences was ultimately disambiguated by the noun at the end of the sequence (e.g., in the example shown in Table 1, only the turtle was depicted with a kite). One character was made more prominent than the other in the context sentences because it was mentioned first three times, was sentence subject twice, and was pronominalized once. In half of the target sequences, the subject was the character already established as prominent (the continue condition), while in the other half, the subject was the less prominent character (the shift condition). The question of interest was whether children's interpretation of the pronouns, measured by their looking preferences for the two characters before the disambiguating information arrived, was influenced by the characters' prominence in the preceding context sentences.

The 3-year-olds in this experiment interpreted the target pronouns as referring to the more prominent character in the story. Thus, during the period of the pronoun's ambiguity, children spent more time looking at the (ultimately) correct referent of the pronoun in the continue than in the shift condition. In subsequent experiments, we found the same continued-subject preference when shorter context stories contained fewer cues to the relative prominence of the two characters. In particular, the combination of sentence-initial position and grammatical subject status was sufficient to establish one referent as more prominent than the other for later pronominal reference. In contrast, the manipulation of discourse prominence had little or no effect on the interpretation of lexical noun phrase subjects.

Table 1

Structure of stimulus stories, Song and Fisher (2005; Experiment 2)

\begin{tabular}{lll}
\hline & Continue & Shift \\
\hline Context & See the turtle and the tiger. & See the tiger and the turtle. \\
& The turtle goes downstairs with the tiger. & The tiger goes downstairs with the turtle. \\
& And he finds a box with the tiger. & And he finds a box with the turtle. \\
Target & Now what does he/the turtle have? Look, he has a kite! (Pronoun vs. Noun)
\end{tabular}


These findings added to previous reports that older children expect subject pronouns to refer to referents already established as prominent in the discourse context. For example, response times in a mispronunciation-detection task suggested that 5-year-olds quickly interpreted a pronoun as a reference to the thematic subject of a preceding story (Tyler, 1983). Similarly, in a sentencefragment completion task, 5-year-olds often misinterpreted pronouns when they were used to switch reference from a clearly established topic or thematic subject to a less prominent character, even though the pronouns' gender made them unambiguous (Tyler, 1984). There is also evidence that initial position can promote referent prominence. Wykes (1983) examined 5-year-olds' ability to use the semantics of a preceding context sentence to infer the plausible antecedent of a pronoun: Note in examples (4-5) that the verbs in the initial sentences have different consequences for who has the pencil, and thus can plausibly give it in the second sentence. Five-year-olds more accurately interpreted the subject pronoun in the second sentence as referring to the contextually plausible antecedent when that plausible antecedent was also the first noun phrase in the preceding sentence.

(4) Jane ${ }_{\mathrm{a}}$ found Susan's pencil. She $\mathrm{a}_{\mathrm{a}}$ gave it to her.

(5) Jane wanted Susan's pencil. She $_{\mathrm{b}}$ gave it to her.

Taken together, these findings suggest considerable continuity in the basic architecture of the sentence comprehension system from age 3 to adulthood. Even 3 -year-olds, like adults, interpret sentences relative to a representation of the current state of the discourse. Referents are ranked in prominence in the 3-year-old's discourse model, and discourse prominence is influenced by some of the same factors that promote referent prominence in adulthood, including subject status and/ or initial position. Finally, discourse prominence affected how 3-year-olds interpret pronouns: like adults, they preferred to interpret a pronoun as maintaining reference to an alreadyprominent character.

\section{Experiment 1}

The current research began to probe the developmental antecedents of these abilities. As a first step, we asked whether even younger children, 2.5-year-olds, would be influenced by the discourse prominence of candidate antecedents in interpreting pronouns. If sensitivity to discourse prominence is a natural and early feature of language comprehension, then even younger children should show sensitivity to the structure of previous sentences when interpreting pronouns.

However, in a pilot experiment, 2.5-year-olds showed no preference for a continued subject interpretation of a subject pronoun. The pilot experiment used the stories (see Table 1) and procedures introduced by Song and Fisher (2005); but 2.5-year-olds did not show a reliable tendency to interpret the pronoun as referring to the character established as prominent in the preceding sentences. If anything, the younger children showed a slight tendency to look longer at the most recently mentioned referent when they heard the ambiguous pronoun in the target sequence.

There are several possible interpretations of these results. First, 2.5-year-olds might not yet have learned that discourse prominence cues such as grammatical subject status or order of mention predict pronoun reference (see Arnold et al., in press, for an argument to this effect). If this interpretation is correct, then recency of mention (affecting prominence in a linguistic representation of the preceding sentences) might be the only discourse prominence cue that sets one character apart. As noted above, recency of mention affects adult pronoun interpretation as 
well-other things being equal, adults prefer recent referents for pronouns (e.g., Clark and Sengul, 1979).

A second possibility is that the stories might have been difficult to understand, perhaps because (a) the two character names in each story began with the same initial phoneme and therefore were relatively confusable and (b) some characters' names (e.g., camel, beaver) may have been unfamiliar to 2.5-year-olds. If so, then children's interpretations of the target pronouns might have been affected by an inaccurate representation of the prior discourse.

Third, and relatedly, it may be that the effects of discourse context on the younger children's pronoun interpretation are qualitatively similar to those found in older children, but are weaker or slower to emerge. To bring discourse context information to bear on pronoun interpretation, children must not only identify the words in the current sentence, but also retrieve aspects of a representation of the prior discourse. Younger children may be slower and more error-prone in doing so, much as they are slower and less accurate in spoken word comprehension (e.g., Fernald et al., 1998; Zangl et al., 2005). If so, we might more readily find evidence of discourse context effects following stories with a stronger discourse manipulation, offering more evidence that one character is more prominent than the other.

To explore these possibilities, we revised the stimulus stories for Experiment 1 as shown in Table 2. First, pairs of character names with different initial phonemes were used (alligator and tiger rather than turtle and tiger). Names with different initial phonemes should be identified more quickly and accurately (e.g., Swingley et al., 1999; Fernald et al., 2001). Second, we chose character names that are listed in a vocabulary checklist for toddlers (the MacArthur CDI Level II; Fenson et al., 1994), because this list includes words that are likely to be known by preschoolers. Third, we removed the word Now, which preceded all target sentences in the pilot experiment, and replaced it with And. Now can indicate a new subtopic (Grosz and Sidner, 1986; Hirschberg and Litman, 1993), and so might have tended to reduce the effect of the discourse manipulation. Fourth, we established one character as a clear topic or thematic subject early in each story by presenting it in a sentence that did not mention the other character. Thus, this character (the alligator in Continue and the tiger in Shift in Table 2) was made prominent by being more frequently mentioned, mentioned first three times, mentioned in subject position twice, and mentioned with a pronoun. Finally, the less prominent character (the tiger in Continue and the alligator in Shift in Table 2) was introduced in a genitive noun phrase in the last context sentence. Introducing a referent in a genitive noun phrase decreases its discourse prominence in adult comprehension (Badecker and Straub, 2002; Gordon et al., 1999). Using a genitive noun phrase also allowed us to remove the secondary character from sentence-final position, reducing any countervailing effect of recency of mention. To the extent that recency of mention affects immediate referent prominence (e.g., Gernsbacher, 1990), the sentence-final character in the previous materials might have tended to compete with the subject character in the selection of the test pronoun's antecedent.

Table 2

Structure of stimulus stories, Experiment 1

\begin{tabular}{lll}
\hline & Continue & Shift \\
\hline Context & See the alligator and the tiger. & See the tiger and the alligator. \\
& On a sunny day, the alligator went outside. & On a sunny day, the tiger went outside. \\
& And he went to the tiger's yard. & And he went to the alligator's yard. \\
Target & And what did he/the alligator find? Look, he found a bucket! (Pronoun vs. Noun)
\end{tabular}




\subsection{Methods}

\subsubsection{Participants}

Sixteen 2.5-year-old children ( $M=31.9$ months; range 28.6-35.1; 9 boys, 7 girls) participated. All were native speakers of English. Six additional children were tested but not included because of a side bias (2), activeness (2), or failure to complete the task (2). Parents completed the short form of the MCDI: Level II (Form A) (Fenson et al., 2000). The median productive vocabulary was 86.5 (of 100 words on the inventory). ${ }^{1}$

\subsubsection{Materials}

Sixteen experimental story items were constructed with the structure shown in Table 2. One additional story was used as a practice trial. The first three sentences of each story were the context sentences; the fourth was the test sentence. Four versions of each story were constructed as shown in Table 2, such that the test sentence either continued the subject of the preceding context or shifted to a new subject, and the subject of the test sentence was realized as a pronoun or as a repeated lexical noun. Subject continuity was manipulated by changing the context sentences (see Table 2). Thus the test sentences and test pictures were the same for the continue and shift versions; any differences in looking patterns across these conditions must be due to the discourse context manipulation.

The 16 story items were created by inserting different pairs of animal names into four story templates. The purpose of the repeated story templates was to reduce the difficulty of the task, giving the stories the repetitive style of many children's storybooks. In all four story templates, one character was made more prominent than the other because it was mentioned first in all three context sentences, mentioned more often (the second context sentence mentioned only one character), established as the subject of the second and third context sentences, and was pronominalized in the third context sentence. The second-mentioned character was demoted to a genitive phrase (e.g., the tiger's yard) in the third context sentence.

The sentences that made up these stories were digitally recorded in a sound-attenuated booth. The materials were spoken by a female native English speaker in a child-directed style. All context sentences were recorded first, then all test sentences, in a random order. Half of the continue-condition contexts were recorded before the corresponding shift-condition contexts, and half of the noun-subject test sentences were recorded before their pronoun-subject counterparts.

For counterbalancing, the 16 story sets were divided into four subsets of four items, with content words in test sentences matched across subsets on number of syllables and initial consonant, and roughly matched in frequency (Francis and Kucera, 1982) and prevalence in young children's productive vocabularies (Fenson et al., 1994). These subsets were combined into four experimental lists, such that each participant experienced four stories in each of the four conditions shown in Table 2, and each story occurred in all conditions across participants. For each experimental list, the 16 stories were presented in a random order, with the constraints that one story in each of the four conditions appeared in each quarter of the list and no more than two stories from the same condition appeared in a row.

\footnotetext{
${ }^{1}$ The Level II vocabulary checklist is intended for children 16-30 months old; the children in this experiment therefore extend beyond the usual range for this instrument. We chose to use this measure because it is readily available and often used, short enough for the parent to complete in the lab, and, by comparison to published norming data, gives us a way to identify children who may be slightly delayed in language development.
} 

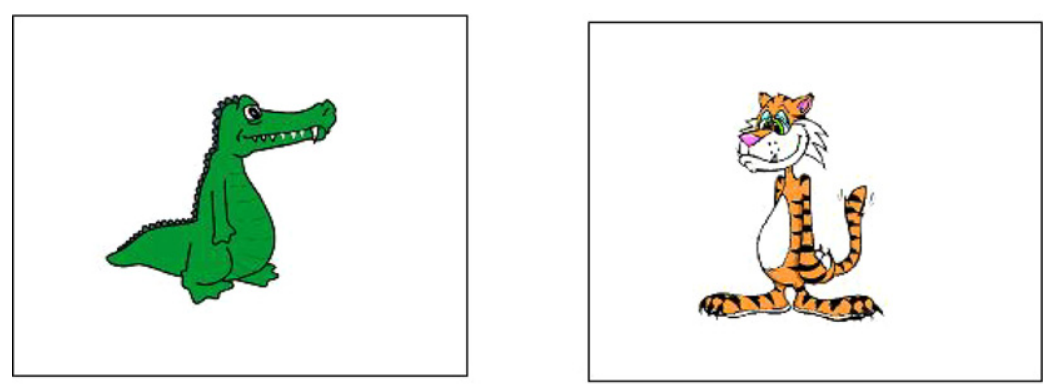

See the alligator and the tiger.
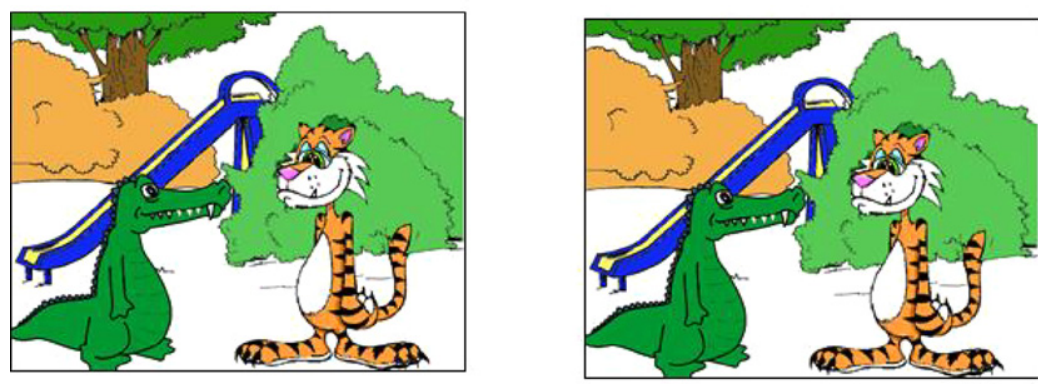

On a sunny day, the alligator went outside.

And he went to the tiger's yard.
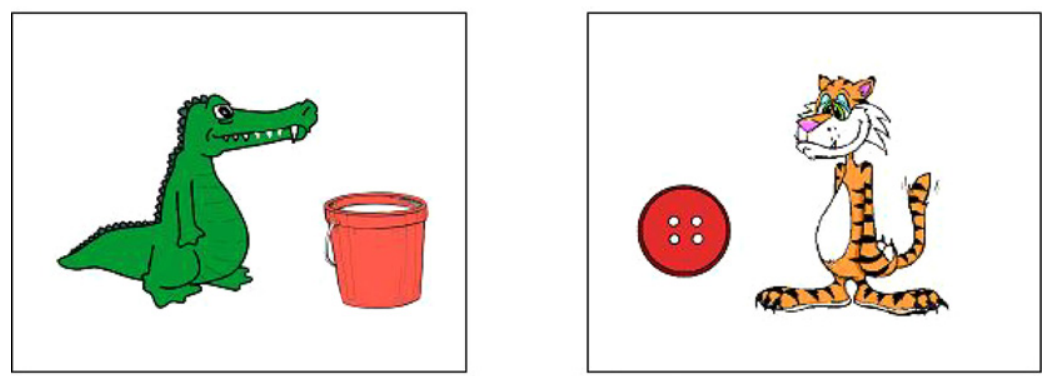

And what did he find? Look, he found a bucket!

Fig. 1. A sample video sequence, Experiment 1.

The stimulus videos and sentences were designed so that the pronoun subjects were ambiguous for several seconds: In the test sequence shown in Fig. 1 (And what did he find? Look, he found a bucket.), bucket is the first word that establishes the referent of the pronoun subject (because only the pictured alligator has a bucket). The onset of the disambiguating word was $3.7 \mathrm{~s}$ after subject onset. The names of the pictured objects accompanying the characters in the same story always started with the same initial consonant, as in the example shown in Fig. 1 (bucket/button). This feature helped to ensure that effective disambiguating information was unavailable until well after the onset of the disambiguating word. In the noun-subject condition the test sentence was unambiguous as soon as the subject noun phrase was identified. The picture matching the test sentence (the correct choice) appeared equally often on the left and right screens within each condition for each child. 


\subsubsection{Apparatus and procedure}

Children sat on a parent's lap facing two $20^{\prime \prime}$ color monitors about $30^{\prime \prime}$ away. The screens were at child's eye level, $12^{\prime \prime}$ apart. The stimulus stories were played from a concealed central speaker. A hidden central camera recorded the child's face during the experiment. Parents wore opaque glasses so they could not see the pictures. After each session, we asked parents to indicate whether they thought their children knew each animal name in the stories.

\subsubsection{Coding}

We coded where children looked (left screen, right screen, or away) during the test sequences, frame by frame, from silent video record. To assess coding reliability, a randomly selected $25 \%$ of the children's data were independently coded by a second coder. The first and second coders agreed on $99.1 \%$ of video frames.

\subsubsection{Data analysis}

We examined the proportion of fixations to the correct screen in a 4 s period beginning at the onset of the subject noun phrase. This $4 \mathrm{~s}$ period ended $300 \mathrm{~ms}$ after the onset of the disambiguating word in the test sequence. Based on previous studies using visual-fixation measures of word recognition, we reasoned that eye movements within $300 \mathrm{~ms}$ of the onset of the disambiguating word were unlikely to be triggered by recognition of that word (e.g., Dahan et al., 2000; Swingley et al., 1999); therefore the $4 \mathrm{~s}$ test period was the effective region of ambiguity for the subject pronoun. To examine the time course of discourse prominence effects on pronoun interpretation, we divided the $4 \mathrm{~s}$ test period into four $1 \mathrm{~s}$ windows. Individual trials were excluded from analysis if the child looked away for more than half of the 6 s period during which the choice pictures were visible after the onset of the subject noun phrase, and looking times were treated as missing within each $1 \mathrm{~s}$ window if the child never looked at either screen during that $1 \mathrm{~s}$ period. These criteria resulted in the exclusion of 13 values (5.1\% of 256 trials) in the first $1 \mathrm{~s}$ window, $12(4.7 \%)$ in the second, $11(4.3 \%)$ in the third, and $11(4.3 \%)$ in the fourth. Preliminary analyses of the test data revealed no significant effects of testing block (the first versus second half of the 16-trial procedure), and no significant interactions of block with the factors of interest; the same was true for all experiments reported in this paper.

\subsection{Results}

Fig. 2 shows the mean proportion of children's fixations to the correct picture within each test window, for noun- and pronoun-subject test sentences.

As shown in the Figure, children's fixations during noun-subject test items rapidly converged on the named target picture, suggesting that the children attended closely to the stories. As we previously found for older children and adults (Song and Fisher, 2005), the timing of the 2.5-year-olds' correct fixations for noun-subject items was not affected by subject continuity. A 4 (window) by 2 (subject continuity) repeated measures ANOVA for noun-subject sentences, conducted separately by subjects $(F 1)$ and by items $(F 2)$, revealed only a main effect of time window $(F 1(3,45)=7.43, p<.001 ; F 2(3,45)=4.89, p<.01)$, indicating that children's fixations to the target increased over time. To estimate how quickly children identified the target word and looked toward the matching picture, we compared the proportion of target fixations in the first $1 \mathrm{~s}$ window to the proportion of target fixations in each subsequent $1 \mathrm{~s}$ window. The proportion of target fixations was significantly higher in the second $(t 1(15)=2.72$, 
Noun Condition

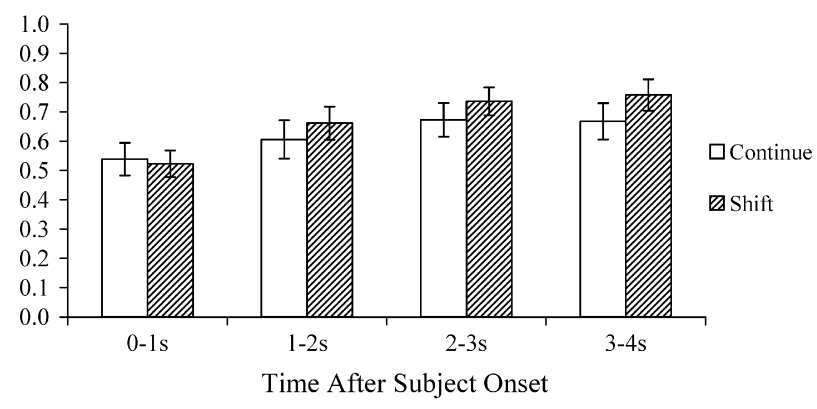

Pronoun Condition

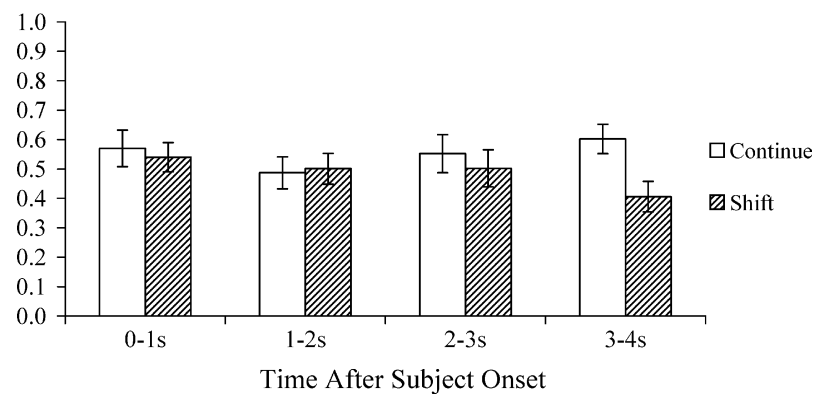

Fig. 2. Mean (S.E.) proportion of correct fixations, Experiment 1.

$p<.01 ; t 2(15)=2.17, p<.05)$, third $(t 1(15)=3.62, p<.01 ; t 2(15)=2.86, p<.01)$, and fourth $(t 1(15)=3.13, p<.01 ; t 2(15)=2.86, p<.01) 1 \mathrm{~s}$ windows than in the first window.

Exploratory analyses revealed that the timing of correct fixations in the noun-subject trials varied with children's vocabulary level, as measured by the CDI-II. We divided the children into high and low vocabulary groups by a median split. Table 3 shows the mean proportion of fixations to the target within each $1 \mathrm{~s}$ window in the noun-subject trials, separately for high- and low-

Table 3

Mean (S.D.) proportion of correct fixations in noun conditions

\begin{tabular}{|c|c|c|c|c|}
\hline & \multicolumn{4}{|c|}{ Time after subject onset } \\
\hline & $0-1 \mathrm{~s}$ & $1-2 \mathrm{~s}$ & $2-3 \mathrm{~s}$ & $3-4 s$ \\
\hline \multicolumn{5}{|l|}{ Experiment 1} \\
\hline High vocabulary & $.55(.12)$ & $.73(.12)$ & $.69(.16)$ & $.70(.23)$ \\
\hline Low vocabulary & $.52(.14)$ & $.54(.15)$ & $.72(.14)$ & $.73(.17)$ \\
\hline \multicolumn{5}{|l|}{ Experiment 2} \\
\hline High vocabulary & $.48(.16)$ & $.67(.17)$ & $.71(.18)$ & $.82(.13)$ \\
\hline Low vocabulary & $.50(.24)$ & $.64(.19)$ & $.73(.17)$ & $.78(.16)$ \\
\hline \multicolumn{5}{|l|}{ Experiment 3} \\
\hline High vocabulary & $.45(.15)$ & $.66(.15)$ & $.75(.12)$ & $.80(.21)$ \\
\hline Low vocabulary & $.49(.16)$ & $.68(.19)$ & $.67(.16)$ & $.72(.19)$ \\
\hline
\end{tabular}


vocabulary children. As the table shows, higher-vocabulary children showed a clearer preference for the matching screen in the second $1 \mathrm{~s}$ window than did the low-vocabulary children. This pattern was confirmed by a 4 (window) by 2 (vocabulary level) repeated measures ANOVA for noun-subject sentences, conducted by subjects, which revealed an interaction of vocabulary with time-window $(F(3,42)=3.14, p<.05)$. Follow-up $t$-tests for each time window revealed a significant effect of vocabulary level on the proportion of target fixations in the second $1 \mathrm{~s}$ window $(t(14)=2.77, p<.05)$, but not in the third or fourth $1 \mathrm{~s}$ windows $(t \mathrm{~s}<1)$. This pattern suggests that the high-vocabulary children were somewhat quicker than were the low-vocabulary children to identify the target word in the noun-subject test items. This finding is consistent with considerable recent evidence that word identification speed and accuracy increases with vocabulary development (e.g., Fernald et al., 2001; Zangl et al., 2005).

In the pronoun condition, as shown in Fig. 2, 2.5-year-olds looked longer at the correct referents of the test pronouns in the continue condition than in the shift condition, in particular during the fourth $1 \mathrm{~s}$ window (3-4 s after pronoun onset). Planned, directional comparisons confirmed that looks to the target picture were significantly higher in the continue than in the shift condition in the fourth $1 \mathrm{~s}$ window $(t 1(15)=2.62, p<.01 ; t 2(15)=3.04, p<.005)$. This continuity preference was not reliable in earlier test windows $(t \mathrm{~s}<1)$.

A 4 (window) by 2 (subject continuity) repeated measures ANOVA for pronoun-subject sentences revealed no significant effects: no main effect of window $(F \mathrm{~s}<1)$, no reliable main effect of subject continuity spanning the four windows $(F 1(1,15)=2.68, p=.12 ; F 2(1,15)=2.40$, $p=.14)$, and no interaction of subject continuity with window $(F 1(3,45)=1.31, p=.28$; $F 2(3,45)=1.60, p=.20)$.

In further analyses, we asked whether the higher-vocabulary children might tend to show an effect of continuity a bit earlier than would the lower-vocabulary children, by examining the looking patterns of high- versus low-vocabulary children across the third and fourth $1 \mathrm{~s}$ windows. Table 4 shows the mean proportion of target fixations for continue- and shift-condition test items in

Table 4

Mean (S.D.) proportion of correct fixations in pronoun conditions

\begin{tabular}{|c|c|c|c|}
\hline & & \multicolumn{2}{|c|}{ Time after pronoun onset } \\
\hline & & $2-3 s$ & $3-4 s$ \\
\hline \multicolumn{4}{|l|}{ Experiment 1} \\
\hline \multirow[t]{2}{*}{ High vocabulary } & Continue & $.68(.23)$ & $.64(.20)$ \\
\hline & Shift & $.43(.29)$ & $.44(.20)$ \\
\hline \multirow[t]{2}{*}{ Low vocabulary } & Continue & $.43(.24)$ & $.57(.20)$ \\
\hline & Shift & $.57(.21)$ & $.38(.23)$ \\
\hline \multicolumn{4}{|l|}{ Experiment 2} \\
\hline \multirow[t]{2}{*}{ High vocabulary } & Continue & $.50(.26)$ & $.67(.25)$ \\
\hline & Shift & $.53(.12)$ & $.43(.07)$ \\
\hline \multirow[t]{2}{*}{ Low vocabulary } & Continue & $.48(.26)$ & $.42(.25)$ \\
\hline & Shift & $.50(.26)$ & $.38(.25)$ \\
\hline \multicolumn{4}{|l|}{ Experiment 3} \\
\hline \multirow[t]{2}{*}{ High vocabulary } & Continue & $.59(.17)$ & $.62(.19)$ \\
\hline & Shift & $.39(.17)$ & $.50(.22)$ \\
\hline \multirow[t]{2}{*}{ Low vocabulary } & Continue & $.47(.20)$ & $.63(.27)$ \\
\hline & Shift & $.53(.24)$ & $.48(.21)$ \\
\hline
\end{tabular}


the third and fourth $1 \mathrm{~s}$ windows, separately for high- and low-vocabulary 2.5-year-olds. As shown in the Table, high-vocabulary children tended to look more at the target picture in the continue than the shift condition, both in the third and fourth $1 \mathrm{~s}$ windows, while low-vocabulary children showed this continuity advantage only in the fourth $1 \mathrm{~s}$ window. This pattern was supported by a 2 (window) by 2 (subject continuity) by 2 (vocabulary level) ANOVA, conducted by subjects, which revealed a significant three-way interaction of continuity, window, and vocabulary level $(F(1,14)=8.16$, $p<.05$ ). To examine the nature of this interaction, we conducted 2 (subject continuity) by 2 (vocabulary level) ANOVAs separately for the third and fourth $1 \mathrm{~s}$ windows. The interaction of vocabulary and continuity was significant in the third $1 \mathrm{~s}$ window $(F(1,14)=8.97, p<.05)$, but not in the fourth $1 \mathrm{~s}$ window $(F(1,14)<1)$. These findings suggest that, not only were the highvocabulary children quicker to identify the character names in the noun condition test trials, but they were also somewhat quicker than were the low-vocabulary children to bring discourse context information to bear on pronoun interpretation.

\subsection{Discussion}

The results of Experiment 1 suggest that, as 2.5-year-olds listened to the experimental stories, they built a representation in which the story referents varied in prominence. Some combination of the cues we manipulated in Experiment 1 - frequency of mention, subject status, first mention and pronominalization - rendered one character more prominent than the other in the child's discourse model. The relative prominence of discourse referents affected the children's interpretation of the ambiguous test pronoun: Like older children and adults, 2.5-year-olds preferred to interpret the pronouns as referring to the character established as more prominent in the story.

The results of Experiment 1 also suggest that 2.5-year-olds, like older children and adults in previous studies (Arnold et al., 2000; Song and Fisher, 2005), need not wait for disambiguating information to interpret a pronoun. The preference for the continued-subject interpretation of a pronoun emerged during the effective period of the pronoun's ambiguity, before the identity of the disambiguating word could reasonably influence children's visual fixations. ${ }^{2}$ Thus, even children under 3 years of age can use discourse prominence information incrementally, to interpret pronouns before all the necessary information is available.

In addition to this qualitative similarity in our findings regarding pronoun interpretation by 2.5-year-olds and older children, the present results revealed quantitative differences between them. The 2.5-year-olds' looking patterns during the pronoun-subject test sentences revealed a reliable continuity advantage 3-4 s after pronoun onset, but little sign of a continuity advantage earlier in the trial. In similar experiments with 3-year-olds (Experiments 2 and 3 of Song and Fisher, 2005), the preference for the continued-subject interpretation was not entirely dissimilar: the continuity advantage in the 3-year-olds' data was largest at the same point in the trial, 3-4 s after pronoun onset, and at its peak was similar in magnitude to the continuity advantage found in the present experiment. However, the 3-year-olds' continuity advantage also differed in that it began to emerge between 1 and $2 \mathrm{~s}$ after pronoun onset, and was maintained during the rest of the $4 \mathrm{~s}$ test

\footnotetext{
${ }^{2}$ Recall that the $4 \mathrm{~s}$ period of ambiguity extended $300 \mathrm{~ms}$ beyond the onset of the disambiguating word. We assumed that eye movements within $300 \mathrm{~ms}$ of the disambiguating word's onset were unlikely to be influenced by the word's identity, based on past investigations of word identification speed and accuracy in a two-choice looking-preference task (e.g., Fernald et al., 1998), as well as eye-tracking studies of older preschoolers' sentence comprehension (e.g., Trueswell et al., 1999). However, in all experiments reported here, we also analyzed the proportion of target fixations during the first $700 \mathrm{~ms}$ of the fourth test window, ending at the onset of the disambiguating word. In each experiment we found a significant continuity advantage during this shorter time-window.
} 
window, resulting in a significant main effect of subject continuity across the four test windows. Thus, 2.5-year-olds in the present experiment showed an effect of the discourse manipulation that was similar to that shown by the 3-year-olds in our previous experiments, but was slower to emerge.

The analyses relating performance in the present experiment to vocabulary level, although post hoc and therefore to be interpreted with caution, revealed that higher-vocabulary 2.5 -yearolds were somewhat quicker to shift their gaze to the target during noun-subject test sentences, and also showed a somewhat earlier continued-subject preference during pronoun-subject test trials. These patterns are consistent with prior evidence that younger children tend to be slower in processing speech on-line (e.g., Cole and Perfetti, 1980; Fernald et al., 2006; Fernald et al., 1998; Tyler and Marslen-Wilson, 1981), and that advances in word identification speed and accuracy are better predicted by vocabulary size than by age (Zangl et al., 2005).

\section{Experiment 2}

The goal of Experiment 2 was simply to replicate the effect of discourse continuity on pronoun interpretation found in Experiment 1. Experiment 2 was like Experiment 1 except that the materials were revised in an attempt to make the stories even easier for the children to understand. In Experiment 1, some of the animal names in the stories were less well known to the children than others, as judged by their parents. Eight of the experimental stories contained names that nearly all of the parents thought their children knew (at least 15 of the 16 parents), while the other eight stories contained names that some parents thought their children did not know. The parents' judgments were consistent with vocabulary norms for children 16-30 months of age (Fenson et al., 1994). In Experiment 2, we chose to use only the 16 character names from the eight 'easy' stories of Experiment 1.

\subsection{Methods}

\subsubsection{Participants}

Another group of 162.5 -year-olds ( $M=32.0$ months; range 28.6-34.3; 10 boys, 6 girls) was tested. Six additional children were tested but not included because of a side bias (3), activeness (2), or parental report of a language delay (1). Two other children (1 boy, 1 girl) were excluded because their productive vocabularies, measured using the MCDI-II, were at or below the fifth percentile for children 28-30 months old in a norming study for the Level II inventory (Fenson et al., 2000). The median productive vocabulary of the included children was 80.5.

\subsubsection{Stimuli}

We used the eight pairs of character names that were found to be easy based on parents' reports in Experiment 1. We generated 16 experimental stories by using each character name twice, once each in the first and second half of the 16 trials. In the second half of the trials, the character names were re-paired. One additional story was constructed for use as a practice trial.

An additional change in the materials of Experiment 2 was that each picture accompanying the stories appeared on the screens a bit longer, to slow down the pacing of the stories. The pictures accompanying the first context sentence were shown for 6 rather than $5 \mathrm{~s}$, the pictures accompanying the second and third context sentences were shown for 12 rather than $10 \mathrm{~s}$, and those accompanying the test sentence were displayed for 8 rather than $7 \mathrm{~s}$; the blank-screen silent interval between stories was $3 \mathrm{~s}$ long. Despite these changes, however, the timing of the test period within which we measured target fixations remained the same: the noun or pronoun subject in the test 
sentences began $1 \mathrm{~s}$ after picture onset, and the effective period of ambiguity for pronoun-subject test sentences was $4 \mathrm{~s}$, as in Experiment 1, ending $300 \mathrm{~ms}$ after the onset of the disambiguating word.

\subsubsection{Apparatus and procedure}

The apparatus and procedure were identical to those of Experiment 1.

\subsubsection{Coding and data analysis}

Coding and data analysis were carried out as for Experiment 1. Five trials for one child were not video-recorded due to experimenter error and were treated as missing in the analysis. Individual trials were also excluded from analysis using the same criteria as for Experiment 1; a total of 20 trials $(7.8 \%$ of 256 trials) were excluded in the first $1 \mathrm{~s}$ window, $17(6.6 \%)$ in the second, $16(6.3 \%)$ in the third, and $16(6.3 \%)$ in the fourth. ${ }^{3}$ The primary and reliability coders agreed on $97.1 \%$ of video frames.

\subsection{Results}

As shown in Fig. 3, the results of Experiment 2 closely duplicated those of Experiment 1. During the noun-subject trials, children's visual fixations quickly converged on the correct screen. The proportion of correct fixations in the noun conditions varied significantly with test window $(F 1(3,45)=15.00, p<.001 ; F 2(3,45)=22.09, p<.001)$, but was unaffected by subject continuity $(F \mathrm{~s}<1)$. As in Experiment 1 , the proportion of target fixations was significantly elevated in the second, third, and fourth $1 \mathrm{~s}$ windows relative to the first $1 \mathrm{~s}$ window (window 2: $t 1(15)=2.79, \quad p<.01 ; \quad t 2(15)=4.44, \quad p<.001 ; \quad$ window $3: \quad t 1(15)=3.37, \quad p<.005 ;$ $t 2(15)=5.37, p<.001 ;$ window $4: t 1(15)=5.77, p<.001 ; t 2(15)=7.05, p<.001)$.

In Experiment 2, the timing of correct fixations in the noun-subject conditions did not vary with children's vocabulary levels, as measured by the CDI-II. As shown in Table 3, low-and highvocabulary children showed a similar preference for the matching screen in the second, third, and fourth $1 \mathrm{~s}$ windows. A 4 (window) by 2 (high versus low vocabulary) repeated measures ANOVA for noun-subject sentences, conducted by subjects, revealed no interaction of vocabulary with time-window $(F<1)$. The disappearance of the vocabulary effect in the noun conditions of Experiment 2 could be due to the changes in the materials relative to Experiment 1: recall that we used a subset of the character names of Experiment 1, those that were most likely to be familiar to children at this age. Both low- and high-vocabulary children might have been near ceiling performance in recognizing the familiar character names and finding their referents.

During the pronoun-subject test sentences, children were more likely to look at the correct picture in the continue than in the shift condition. This preference again emerged in the fourth $1 \mathrm{~s}$ window $(t 1(15)=1.90, p<.05 ; t 2(15)=1.85, p<.05)$, but not in the earlier test windows $(t \mathrm{~s}<1)$. An analysis of children's fixations across the four test windows revealed no significant main effect of subject continuity or of window $(F \mathrm{~s}<1)$; the interaction of subject continuity and window was reliable by items but not by subjects $(F 1(3,45)=2.14, p=.11 ; F 2(3,45)=3.02, p<.05)$.

As for the noun-subject test trials, the timing of the continuity effect in the pronoun-subject trials of Experiment 2 did not strongly depend on vocabulary level: an analysis of the pronoun-

\footnotetext{
${ }^{3}$ Although the choice pictures were visible for $7 \mathrm{~s}$ after subject onset in Experiment 2, we eliminated trials using the same criterion as in Experiment 1, based on whether children looked away for more than half of the $6 \mathrm{~s}$ period after subject onset.
} 

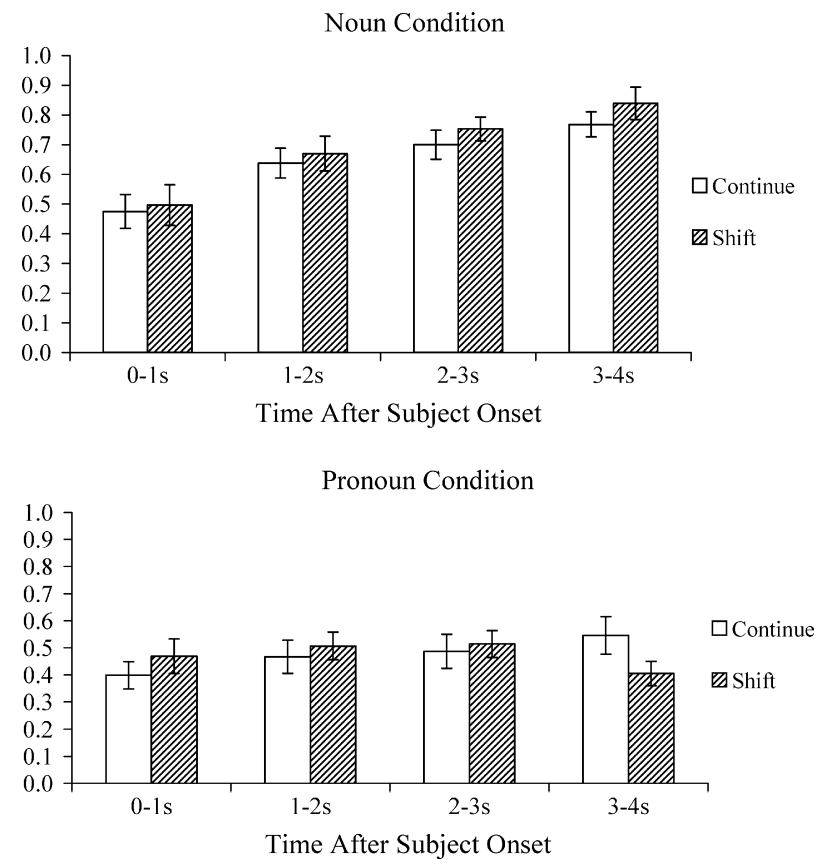

Fig. 3. Mean (S.E.) proportion of correct fixations, Experiment 2.

subject test data in the third and fourth $1 \mathrm{~s}$ windows did not reveal the significant three-way interaction of window, continuity and vocabulary level found in Experiment $1(F(1,14)=1.76$, $p=.206)$. Notice, however, in Table 4 , that the high-vocabulary children showed a numerically stronger continued-subject preference in the fourth $1 \mathrm{~s}$ window than did the low-vocabulary children.

\subsection{Discussion}

The results of Experiment 2 replicated the key findings of Experiment 1: 2.5-year-olds' interpretation of ambiguous pronouns was affected by the discourse prominence manipulation. When several discourse cues - frequency of mention, subject status, order of mention, and pronominalization - were combined to promote the prominence of one character, 2.5-year-olds preferred to interpret a pronoun as referring to that more prominent story character. Also as in Experiment 1, this continuity advantage was detectable in the period of the pronoun's ambiguity, suggesting that 2.5-year-olds need not wait for the arrival of disambiguating information to interpret a pronoun. The continuity advantage emerged with roughly the same timing found in Experiment 1: Children directed more of their attention to the matching screen in continue than in shift test trials, but did so only late in the trial, 3-4 s after pronoun onset.

\section{Experiment 3}

The materials of Experiments 1 and 2 'stacked the deck' in favor of finding discourse prominence effects on pronoun interpretation in very young children, by combining multiple cues to discourse prominence. In particular, one character was mentioned more often in the 
context sentences, increasing the likelihood that children would view that character as the true thematic subject of the story, the one the story was about. In contrast, previous experiments with 3-year-olds have isolated first mention and/or subject status alone as sufficient to establish one character as more prominent than the other in the 3-year-olds' representation of a story (e.g., Experiment 4 in Song and Fisher, 2005).

In a third experiment, we tested the robustness of 2.5-year-olds' sensitivity to discourse prominence by asking whether 2.5-year-olds, like the older children in our previous research, would show sensitivity to discourse structure even when the stimulus stories isolated first mention and/or subject status as the only supports for discourse prominence. A sample story is shown in (6). In each brief story, a target sentence containing an ambiguous pronoun was preceded by only two context sentences. One character ( $\operatorname{dog}$ in (6)) was established as more prominent than the other (horse) in the context sentences because it (a) was mentioned sentence-initially twice and (b) was established as a grammatical subject once. The two characters were mentioned equally often in the context sentences, and neither character was invoked using a pronoun.

\section{Context: Look at the dog and the horse.}

On a sunny day, the dog walked with the horse to the park.

Target: And what did he/the dog see? Look, he saw a balloon!

These materials will also allow us to test an alternative interpretation of the results of Experiments 1 and 2. In the materials of Experiments 1 and 2, although half of the pronounsubject test sentences were continued-subject sentences and half were shifted-subject test sentences, each context story contained a continued-subject pronoun. Thus, the majority of the pronoun subjects that children heard during the experiment turned out to refer to the subject of the preceding sentence. In principle, children could have developed a bias to interpret pronouns as continued subjects during the experiment itself. Inspection of the results of Experiments 1 and 2 did not support this interpretation: In both experiments, the continuity advantage in pronounsubject test trials appeared in the first half of the trials, suggesting that this advantage was not due to strategy change during the experiment. The materials of Experiment 3, however, removed the possibility that children could learn to treat pronouns as continued subjects during the experiment. Only the test sentences contained pronouns, and children heard shifted- and continued-subject pronouns equally often.

\subsection{Methods}

\subsubsection{Participants}

Twenty-four 2.5-year-olds ( $M=31.9$ months; range 29.6-35.1; 11 boys, 13 girls) participated in Experiment 3. Two additional children were tested but not included, because of a side bias (1), or because the child's productive vocabulary, measured using the MCDI-II, was at or below the fifth percentile for children 28-30 months old in a norming study for the Level II inventory (1; Fenson et al., 2000). The median productive vocabulary of the included children was 94.

\subsubsection{Stimuli}

We generated 16 new experimental stories with the structure shown in (6). One additional story was used as a practice trial. The experimental stories used the same character names that were used in Experiment 2. As in Experiment 2, each character name was used twice, once each in the first and second half of the 16 trials; in the second half of the trials, we re-paired the 
character names. The timing of the presentation of pictures and sentences was as in Experiment 2. The effective period of ambiguity for the pronoun was $4 \mathrm{~s}$, as in both Experiments 1 and 2 .

\subsubsection{Apparatus and procedure}

The apparatus and procedure were identical to those of Experiments 1 and 2.

\subsubsection{Coding and data analysis}

Coding and data analysis were carried out as for the previous experiments. Individual trials were excluded from analysis using the same criteria as in Experiments 1 and 2; a total of 24 trials (6.3\% of 384 trials) were excluded in the first $1 \mathrm{~s}$ window, $19(5.0 \%)$ in the second, $18(4.7 \%)$ in the third, and $21(5.5 \%)$ in the fourth. The primary and reliability coders agreed on $97.8 \%$ of video frames.

\subsection{Results}

As shown in Fig. 4, the results of Experiment 3 closely resembled those of Experiments 1 and 2. During the noun-subject trials, children's visual fixations quickly converged on the correct picture. The proportion of correct fixations in the noun condition changed significantly across the test windows $(F 1(3,69)=21.00, p<.001 ; F 2(3,45)=29.47, p<.001)$, but did not vary with subject continuity $(F \mathrm{~s}<1)$. Again, children looked significantly longer at the target in the second, third, and fourth $1 \mathrm{~s}$ windows following the noun's onset than they did in the first $1 \mathrm{~s}$ window (window 2: $t 1(23)=5.35, p<.001 ; t 2(15)=6.35, p<.001$; window $3: t 1(23)=5.26$, $p<.001 ; t 2(15)=5.54, p<.001$; window $4: t 1(23)=5.54, p<.001 ; t 2(15)=6.77, p<.001)$.
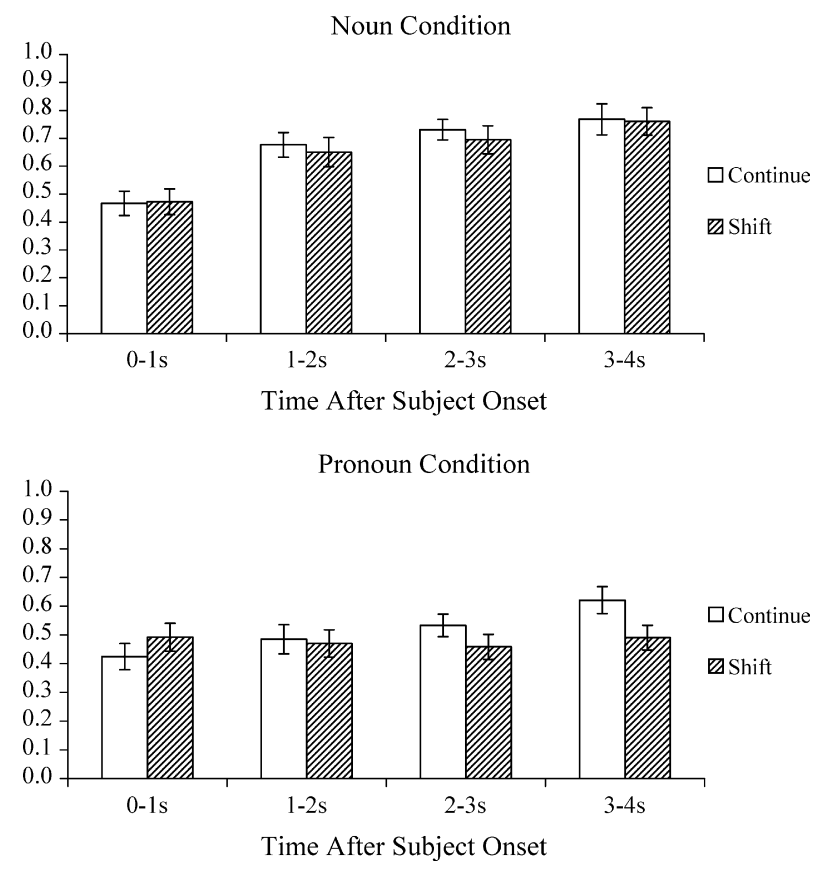

Fig. 4. Mean (S.E.) proportion of correct fixations, Experiment 3. 
As in Experiment 2, the timing of target fixations in the noun-subject conditions did not vary with children's vocabulary levels, as measured by the CDI-II. Table 3 shows that both high- and low-vocabulary 2.5-year-olds showed an elevated preference for the target picture by the second $1 \mathrm{~s}$ test window. A 4 (window) by 2 (low versus high vocabulary) repeated measures ANOVA for noun-subject sentences, conducted by subjects, revealed only the main effect of window $(F(3,66)=20.39, p<.001)$, and no interaction of vocabulary with window $(F 1(3,66)=1.36$, $p>$.26). In both Experiments 2 and 3, we used a reduced set of animal names that were selected to be highly familiar to children of this age; the lack of a vocabulary effect in the timing of spoken word identification in this context can be regarded as a ceiling effect, indicating that the character names were indeed fairly easy to identify for children at this age.

During the pronoun-subject test sentences, children were more likely to look at the correct picture in the continue than in the shift condition. This preference again emerged in the fourth $1 \mathrm{~s}$ window $(t 1(23)=2.75, p<.01 ; t 2(15)=2.17, p<.05)$, but not in the earlier test windows (window 1 and 2: $t \mathrm{~s}<1$; window $3: t 1(23)=1.30, p=.10 ; t 2(15)=1.76, p=.05$ ). An analysis of children's fixations across the four test windows revealed no significant main effects of subject continuity $(F 1<1 ; F 2(1,15)=3.00, p=.10)$ or of window $(F 1(3,69)=2.04, p=.12 ; F 2$ $(3,45)=1.86, p=.15)$ and no significant interaction of subject continuity and window $(F 1(3,69)=2.34, p=.08 ; F 2(3,45)=1.82, p=.16)$.

As in Experiment 1, however, exploratory analyses suggested that the timing of the continuity preference in the pronoun-subject conditions varied with the children's vocabulary level. As shown in Table 4, high- and low-vocabulary children both showed a stronger preference for the target picture in the continue than in the shift condition in the fourth $1 \mathrm{~s}$ window; the high-vocabulary children showed a similar continuity advantage in the third $1 \mathrm{~s}$ window as well, while the lowvocabulary children did not. This pattern was supported by a 2 (window) by 2 (subject continuity) by 2 (vocabulary level) ANOVA, conducted by subjects, which revealed a three-way interaction of continuity, window, and vocabulary level $(F(1,22)=6.90, p<.05)$. To examine the nature of this interaction, we conducted 2 (subject continuity) by 2 (vocabulary level) ANOVAs separately for the third and fourth $1 \mathrm{~s}$ windows. The interaction of vocabulary and continuity was significant in the third $1 \mathrm{~s}$ window $(F(1,22)=6.65, p<.05)$, but not in the fourth $(F<1)$. Again, these findings suggest that the high-vocabulary children were somewhat quicker than were the low-vocabulary children to bring discourse context information to bear on pronoun interpretation.

\subsection{Discussion}

The results of Experiment 3 again show that 2.5-year-olds use discourse prominence information to interpret ambiguous pronouns. The continued-subject preference in pronoun interpretation emerged in Experiment 3 despite the substantial reduction in discourse prominence cues relative to Experiments 1 and 2. The 2.5-year-olds in Experiment 3 preferred to interpret an ambiguous pronoun as referring to the character placed in subject and initial position in the preceding sentences; as in previous experiments, they arrived at this interpretation while the pronoun was still ambiguous.

The results of Experiment 3 also rule out an alternative explanation of the continued-subject preference documented in Experiments 1 and 2. Because pronouns were used equally often to refer to shifted and continued subjects during the experiment, children could not have learned to treat pronouns as references to the previous subject in the course of the experiment.

Finally, the results of Experiment 3 also support the hypothesis that the speed with which children bring discourse context information to bear on pronoun interpretation changes with age 
and vocabulary development. As before, the 2.5-year-olds' continued-subject preference in pronoun trials emerged only late in the period of the pronoun's ambiguity, 3-4 s after pronoun onset. Similar experiments with 3-year-olds showed a continuity preference that began to emerge much earlier in the trial (Song and Fisher, 2005). In addition, as in Experiment 1, high-vocabulary 2.5-year-olds tended to show a slightly earlier continued-subject preference in pronoun interpretation than did low-vocabulary 2.5 -year-olds.

\section{General discussion}

The present research suggests that, even before the third birthday, children's sentence comprehension is influenced by their representation of the prior discourse context. In three experiments, 2.5-year-olds showed consistent sensitivity to the preceding sentences when interpreting pronouns. While listening to short stories, children created a representation of each story that influenced their interpretation of the test sequences. After hearing an ambiguous pronoun, children's search for a referent was affected by their model of the prior discourse.

Crucially, in that discourse model, one character was singled out as the more prominent character, and thus was more readily linked to an ambiguous pronoun in the subsequent sentence. In Experiments 1 and 2, we succeeded in promoting the prominence of one character in the 2.5-year-olds' discourse model by manipulating some of the same factors that have been shown to affect referent prominence in adults' or older children's discourse representations: frequency of mention, first mention, subject status, and pronominalization. Experiment 3 showed that the combination of first mention and subject status alone was sufficient to promote the relative prominence of a character in 2.5-year-olds' discourse representations. Moreover, in the present experiments, children showed evidence of selecting a referent for the ambiguous test pronouns before the arrival of disambiguating information at the end of the target sequence. This finding illustrates the fundamentally predictive or incremental nature of the language comprehension system.

These new findings, taken together with our previous results with older children (Song and Fisher, 2005), suggest that the basic architecture of the young child's sentence processing system shares many fundamental features with the mature system.

\subsection{Integrating social-contextual cues into the discourse model}

Over the past 10 years, several researchers have begun to explore the young child's ability to integrate cues from the social context into language comprehension. Between the first and second birthdays, children show increasingly sophisticated sensitivity to the referential cues that accompany speech (e.g., Baldwin et al., 1996; Baldwin and Moses, 2001). By about 2 years of age, children integrate linguistically-presented information (e.g., Let's go find the gazzer!) with subsequent gestures or facial expressions to attach a new label to the target of the speaker's search for an object, but not to objects picked up and rejected during the search (Tomasello and Barton, 1994). Children's language production also shows the effects of joint speaker-listener attention on referent prominence: young Inuktitut speakers used null pronouns for items that had not yet been explicitly mentioned, if speaker and listener shared joint attention to the referent at the time (Skarabela and Allen, 2002).

These social-contextual cues are distinct from the linguistic contextual cues that we examined in the present study. However, children's ability to integrate situationally-provided referential cues such as eye gaze and gesture with linguistic information would seem to require the same 
kind of incrementally created propositional model of the discourse and its setting that is assumed to underlie adult language comprehension. A propositionally encoded situation model provides a representational space within which social and linguistic cues to the speaker's focus of attention can be combined to influence language comprehension. The present findings add to this literature by showing that by age 2.5 , children can use purely linguistic cues, in the absence of referential cues, to focus their attention on one of two story characters, thus treating that character as the thematic subject, the one the local stretch of discourse is about.

\subsection{The time-course of discourse prominence effects}

Our results revealed one striking difference between younger and older listeners. The 2.5-year-olds in the present experiments were quite slow to show the effects of discourse prominence in pronoun interpretation. In all three experiments, their preference for the most prominent story character was detectable only in the latest test window, beginning $3 \mathrm{~s}$ after pronoun onset. The time-course of this effect contrasts with earlier findings from 3-year-olds. When 3-year-olds heard stories similar in complexity to the materials of Experiments 1 through 3 (Song and Fisher, 2005), their preference for the more prominent antecedent began to emerge much earlier in the $4 \mathrm{~s}$ period of ambiguity, resulting in a robust main effect of prominence across the four $1 \mathrm{~s}$ test windows. In the present experiments, the data exhibited little sign of a continuedsubject preference in these earlier test windows, suggesting that 2.5-year-olds are slower than 3 -year-olds to bring information from the discourse model to bear on pronoun interpretation. The speed with which discourse context influences pronoun interpretation increases still more in adulthood: In an eye-tracking comprehension task, adult listeners' preference for the more prominent character began to emerge about 200-400 ms after the onset of an ambiguous pronoun (Arnold et al., 2000).

It is hardly surprising that younger children should be slower to show a systematic effect of discourse context information during language processing. After all, young children are generally slower and less accurate in spoken word and sentence comprehension (e.g., Cole and Perfetti, 1980; Fernald et al., 1998; Fernald et al., 2006). One might expect that the effects of slowing would be particularly dramatic in computationally more involved aspects of language processing. To interpret an anaphoric expression, children must retain information derived from the preceding utterances, use the ambiguity of the anaphoric phrase to prompt the retrieval of information from the discourse model, and update the discourse model in response to the current sentence (e.g., Bock and Brewer, 1985; Garrod and Sanford, 1994). To the degree that young children and adults differ in processing speed, in working memory capacity, and/or in efficiency in selecting one referent among competitors (e.g., Adams and Gathercole, 2000; Diamond, 1985; Kail, 1992), we should expect to find a developmental acceleration in the online use of prior context in sentence comprehension.

In some cases, slow recruitment of discourse context information may cause a qualitative difference in the way sentence processing works. In our experimental materials, we delayed the arrival of disambiguating information for several seconds, in order to measure a slowly developing effect of the discourse context. But if discourse context information is very slow to influence pronoun interpretation in the developing comprehension system, then in many ordinary sentences, this information may simply arrive too late to be of use. Similar qualitative effects of simple slowness have been suggested to explain effects of cognitive aging on the online use of semantic context in the resolution of lexical ambiguity. Dagerman et al. (2006) reported that young and elderly adults were equally good at using prior biasing context to resolve lexical 
ambiguity in an offline task, but that elderly adults failed to use this information (in time) during online comprehension. Their analysis suggested that variations across different experiments in whether or not elderly adults made good use of context information to interpret ambiguous words could be accounted for by variations in (a) the time available to retrieve and make use of context information, and (b) the strength of the context manipulation.

Given preschoolers' slow recruitment of discourse context information in pronoun interpretation, we might expect to find similar variation across experiments in whether any context effects are found at all, depending on the timing of the task. Consistent with this argument, an experiment recently looked for discourse prominence effects in 5-year-olds' interpretation of ambiguous pronouns, in materials in which the disambiguating information arrived within $1 \mathrm{~s}$ of the onset of the pronoun (Arnold et al., in press). Arnold et al. found little evidence of discourse prominence effects, although they found evidence for rapid use of the local lexical cue of pronoun gender. The Arnold et al. (in press) and the Song and Fisher (2005) materials differed in several ways, including the timing of the disambiguating information, and the strength of the discourse context manipulation (e.g., two context sentences versus one). The difference in the findings was probably at least partly due to the timing differences between the two experiments: a pilot experiment in our lab (Song, 2001) detected no effect of discourse prominence in 3-year-olds' pronoun comprehension when the disambiguating information arrived very soon after the ambiguous pronoun. Future research will need to further examine this question, varying the strength of the discourse prominence manipulation, as well as the timing of disambiguating information, to investigate the emergence and the time-course of discourse prominence effects in the developing comprehension system.

\subsection{Remaining questions}

Taken together with the previous findings with older children reviewed in section 1 , the current research suggests that - at least when two context sentences are available - young children can exploit cues such as first mention or grammatical subject status to rank the intended prominence of various referents in their representation of a story, and thus to guide later pronoun interpretation. These findings raise a number of questions for future research.

First, what was the role of the pronoun itself in prompting the continued-subject preference? Adult listeners appear to use a pronoun (or presumably a subject-less verb, in a language permitting null pronouns) as a cue to seek a prominent antecedent, and therefore they rapidly show effects of discourse context in pronoun interpretation. Arnold et al. (in press) have termed this the expectancy hypothesis, arguing that the ranking of referents by discourse salience, based on a variety of linguistic and non-linguistic cues, allows listeners to predict that highly prominent referents will be invoked again in upcoming sentences. Children's slower recruitment of discourse context information leaves open the possibility that they do not yet use the presence of a pronoun as a cue to immediately consult the discourse model; instead, they may possess a more general expectation that the most prominent character will continue to be centrally involved in subsequent sentences. For example, children might assume that the more prominent character is likely to be involved, even in a sentence with less clear cues to seek a prominent antecedent (e.g., "And what happened?" instead of "And what did he see?"). Future experimentation will examine the role of the referential content of the test sentence, and the lexical form of anaphoric phrases (e.g., ambiguous full noun phrase versus pronoun), on the strength and time-course of children's recruitment of discourse prominence cues during sentence interpretation. 
Second, what is the source of young children's sensitivity to discourse prominence cues in pronoun interpretation? Two general classes of possibilities have been proposed.

One possibility is that children may simply learn that an entity that a speaker has recently mentioned, has mentioned first in a sentence, or has established as a grammatical subject, is likely to be invoked again in subsequent sentences, and tends to be the referent of a pronoun. Arnold and her colleagues have argued that distributional learning is the source of the listener's expectancy that highly prominent referents will be mentioned again (e.g., Arnold et al., 2005, in press); their account is similar to the competition model proposed by Bates and MacWhinney (1989). On this view, children should be slow to develop sensitivity to discourse prominence cues, because of their low cue validity. For example, Arnold (1998) found that only $64 \%$ of subject pronouns in a sample of children's stories referred to the subject of the preceding clause. Given the relative unreliability of grammatical role and order as cues to pronoun reference, Arnold et al. (2005, in press) argued that (a) it should take children a long time to learn that these cues predict pronoun reference at all, and (b) these cues, once learned, should be weighted weakly in a multiply constrained comprehension system.

In contrast, we have speculated that recent mention, first mention, or grammatical subject status might naturally promote the prominence of referents in an incrementally-constructed discourse representation, as side effects of ordinary sentence comprehension (Song and Fisher, 2005). For example, an entity mentioned first in a sentence provides a context for the encoding of the rest of the sentence, and thus may become salient in the representation of sentence meaning (e.g., Gernsbacher, 1990; MacWhinney, 1977). In addition, referents that are established as grammatical subjects tend to play prominent semantic roles, including roles involving the causation, control, or experiencing of events (e.g., Jackendoff, 1990). Although the nature of the semantic asymmetry between subjects and non-subjects can be described in many ways, diverse linguistic analyses converge on the fundamental insight that subjects convey prominent semantic roles (cf. Coppola and Newport, 2003). If these views have merit, then children might not have to learn from scratch that subjects, or first-mentioned entities, should be treated as prominent in a semantically-interpreted discourse model. Instead, their prominence in the model may follow from their prominence in the meaning of each sentence. This natural-prominence proposal leads to the prediction that young children might be sensitive to discourse prominence cues such as order of mention or grammatical subject status earlier in development than we might expect based on cue validity alone.

The natural-prominence and cue-validity proposals are not mutually exclusive. Despite broad similarities across languages in the signaling of discourse prominence (centrally including the prominence of subject and initial referents), languages vary in the details of the devices they offer for marking discourse prominence. For example, Japanese speakers must learn that the morpheme - wa identifies a topic, and is thus the preferred antecedent for a subsequent null pronoun (Iida, 1998). Cue validity and salience must be important features of any account of how such fundamentally arbitrary cues are learned. The natural-prominence view proposes only that it is not obvious that all cues to salience are treated as arbitrary by the child's language processing system, and therefore that cue validity calculations are unlikely to be the only predictors of developmental sequence.

\subsection{Vocabulary effects}

The vocabulary effects revealed in the post-hoc analyses of the present data suggest interesting individual differences in the timing of context use within the 2.5-year-old age group. 
High-vocabulary 2.5-year-olds tended to look toward the continued-subject referent a bit earlier than did low-vocabulary 2.5-year-olds. These post-hoc findings must of course be interpreted with caution, but are bolstered by the fact that the vocabulary effect emerged in the same way in both Experiments 1 and 3, and was reflected in a consistent numerical difference between highand low-vocabulary children in Experiment 2. These data suggest that, with age and experience, children become more efficient in their use of discourse context information in pronoun interpretation.

The apparent relationship between vocabulary and the speed with which the 2.5 -year-olds exploited discourse context cues could be construed as consistent with either the naturalprominence or the cue-validity account. The vocabulary effects suggest a role for language experience in the recruitment of discourse context cues during sentence interpretation. The nature of this role, however, is open to many interpretations. Vocabulary growth is related to the extent and diversity of language experience (e.g., Hoff, 2003). Older or higher-vocabulary children therefore may have encountered more of the linguistic data that would be needed to learn the set of linguistic cues (including recent mention, first mention, and subject status) that predict which referents are highly prominent, and therefore likely to be mentioned again. This line of reasoning would link age and vocabulary changes directly to the learning of discourse-context cues, and would be consistent with the cue-validity account.

At the same time, vocabulary growth is strongly associated with language processing efficiency (e.g., Fernald et al., 2006). Older or higher-vocabulary children are more efficient at identifying familiar words in the linguistic input. These differences in the efficiency of word- and sentence-level processing could indirectly affect children's ability to use discourse information in our task, independent of the children's knowledge of the utility of discourse prominence cues. Performance in our task depends on children's ability to accurately identify the words in the stories, parse the sentences, integrate information across sentences, and retrieve story-context information during the test sequences. Children who are less efficient at any or all of these component tasks might be slower (or sometimes unable, depending on the time-course of the task) to take advantage of the discourse context in interpreting an ambiguous pronoun. This possibility would be consistent with the natural-prominence account.

On the other hand, word- and sentence-level processing efficiency should also influence the young child's intake of information from the linguistic environment (see Fernald et al., 2006, for an interesting recent statement of this possibility). Speedy and accurate word-identification would allow children to more accurately represent the linguistic input they encounter, and therefore to learn more of what the input has to offer. Thus, older or higher-vocabulary children might be more likely to detect the predictive value of various cues to discourse prominence. Much additional research will be needed to sort out the tangled effects of language experience and those that follow naturally from the basic architecture of the language processing system.

The present experiments show that sensitivity to discourse prominence begins very early during the course of language acquisition; these findings set the stage for future investigations of how children learn the discourse-pragmatic significance of different anaphoric terms in their native language, and how they develop the ability to consult their model of the discourse with the lightening speed that adults seem to manage.

\section{Acknowledgements}

This research was supported by a grant from NICHD to Cynthia Fisher (HD 44458) and in part by Yonsei University Research Fund of 2006 to Hyun-joo Song. We thank Renée Baillargeon, 
Gary Dell, Susan Garnsey, Adele Goldberg, and Kristine Onishi for many helpful comments, the undergraduate research assistants of the language acquisition lab for their help in data collection, and the parents and children who participated in this research.

\section{References}

Adams, A., Gathercole, S.E., 2000. Limitations in working memory: implications for language development. International Journal of Language and Communication Disorders 35, 95-116.

Allen, S.E.M., 2000. A discourse-pragmatic explanation for argument representation in child Inuktitut. Linguistics 38, 483-521.

Almor, A., 1999. Noun-phrase anaphora and focus: the informational load hypothesis. Psychological Review 106, $748-765$.

Ariel, M., 1990. Accessing NP Antecedents. Routledge, London.

Ariel, M., 2001. Accessibility theory: an overview. In: Sanders, T., Schilperoord, J., Spooren, W. (Eds.), Text Representation: Linguistic and Psycholinguistic Aspects. John Benjamins, Philadelphia, pp. 29-87.

Arnold, J.E., 1998. Reference form and discourse patterns. Unpublished dissertation, Stanford University.

Arnold, J.E., Brown-Schmidt, S., Trueswell, J., Fagnano, M., 2005. Children's use of gender and order of mention during pronoun comprehension. In: Trueswell, J.C., Tanenhaus, M.K. (Eds.), Processing World-Situated Language: Bridging the Language-as-Product and Language-as-Action Traditions. MIT Press, Cambridge, MA, pp. 261-281.

Arnold, J.E., Brown-Schmidt, S., Trueswell, J.C., in press. Children's use of gender and order-of-mention during pronoun comprehension. Language and Cognitive Processes.

Arnold, J.E., Eisenband, J.G., Brown-Schmidt, S., Trueswell, J.C., 2000. The rapid use of gender information: evidence of the time course for pronoun resolution from eyetracking. Cognition 76, B13-B26.

Avrutin, S., 1999. Development of the Syntax-Discourse Interface. Kluwer, Dordrecht.

Badecker, W., Straub, K., 2002. The processing role of structural constraints on interpretation of pronouns and anaphors. Journal of Experimental Psychology: Learning, Memory, and Cognition 28, 748-769.

Baldwin, D.A., Moses, L.J., 2001. Links between social understanding and early word learning: challenges to current accounts. Social Development 10, 309-329.

Baldwin, D.A., Markman, E.M., Bill, B., Desjardins, R.N., Irwin, J.M., 1996. Infants' reliance on a social criterion for establishing word-object relations. Child Development 67, 3135-3153.

Bates, E., 1976. Language and Context: The Acquisition of Pragmatics. Academic Press, New York.

Bates, E., MacWhinney, B., 1989. Functionalism and the Competition Model. In: MacWhinney, B., Bates, E. (Eds.), The Cross-linguistic Study of Sentence Processing. Cambridge University Press, Cambridge, pp. 3-96.

Bock, K., Brewer, W.F., 1985. Discourse structure and mental models. In: Carr, T.H. (Ed.), The Development of Reading Skills. Jossey-Bass, San Francisco, pp. 55-75.

Bock, J.K., Mazzella, J.R., 1983. Intonational marking of given and new information: some consequences for comprehension. Memory and Cognition 11, 64-76.

Brennan, S.E., 1995. Centering attention in discourse. Language and Cognitive Processes 10, 137-167.

Campbell, A.L., Brooks, P., Tomasello, M., 2000. Factors affecting young children's use of pronouns as referring expressions. Journal of Speech, Language, and Hearing Research 43, 1337-1349.

Chafe, W., 1994. Discourse, Consciousness, and Time: The Flow and Displacement of Conscious Experience in Speaking and Writing. The University of Chicago Press, Chicago.

Chambers, C.G., Tanenhaus, M.K., Eberhard, K.M., Filip, H., Carlson, G.N., 2002. Circumscribing referential domains in real-time sentence comprehension. Journal of Memory and Language 47, 30-49.

Chomsky, N., 1981. Lectures on Government and Binding. Foris, Dordrecht.

Clancy, P.M., 1980. Referential choice in English and Japanese narrative discourse. In: Chafe, W. (Ed.), The Pear Stories: Cognitive, Cultural and Lexical Aspects of Narrative Production. Ablex, Norwood, NJ, pp. 127-202.

Clancy, P.M., 1992. Referential strategies in the narratives of Japanese children. Discourse Processes 15, $441-467$.

Clancy, P.M., 1993. Preferred argument structure in Korean acquisition. In: Clark, E.V. (Ed.), Proceedings of the TwentyFifth Annual Child Language Acquisition Research Forum. CSLI, Stanford, pp. 307-314.

Clancy, P.M., 1997. Discourse motivations for referential choice in Korean acquisition. In: Sohn, H., Haig, J. (Eds.), Japanese/Korean Linguistics, vol. 6. CSLI Publications, Stanford, CA, pp. 639-659.

Clark, H.H., Haviland, S.E., 1977. Comprehension and the given-new contract. In: Freedle, R.O. (Ed.), Discourse Production and Comprehension. Ablex, Norwood, NJ, pp. 1-40.

Clark, H.H., Sengul, C.J., 1979. In search of referents for nouns and pronouns. Memory and Cognition 7, 35-41. 
Cloitre, M., Bever, T.G., 1988. Linguistic anaphors, levels of representation, and discourse. Language and Cognitive Processes 3, 293-322.

Cole, R.A., Perfetti, C.A., 1980. Listening for mispronunciations in a children's story: the use of context by children and adults. Journal of Verbal Learning and Verbal Behavior 19, 297-315.

Coppola, M., Newport, E., 2003 November. The emergence of the grammatical category of subject in Home Sign: evidence from family-based gesture systems in Nicaragua. Paper Presented at the 28th Boston University Conference on Language Development, Boston, MA.

Dahan, D., Swingley, D., Tanenhaus, M.K., Magnuson, J.S., 2000. Linguistic gender and spoken-word recognition in French. Journal of Memory and Language 42, 465-480.

Dagerman, K.S., MacDonald, M.C., Harm, M.W., 2006. Aging and the use of context in ambiguity resolution: complex changes from simple slowing. Cognitive Science 30, 311-345.

Deutsch, W., Pechmann, D., 1982. Social interaction and the development of definite descriptions. Cognition 11, $159-184$.

Diamond, A., 1985. Development of the ability to use recall to guide action, as indicated by infants' performance on AB. Child Development 56, 868-883.

Emslie, H.C., Stevenson, R.J., 1981. Pre-school children's use of articles in definite and indefinite referring expressions. Journal of Child Language 8, 313-328.

Ehrlich, K., Rayner, K., 1983. Pronoun assignment and semantic integration during reading: eye movements and immediacy of processing. Journal of Verbal Learning and Verbal Behavior 22, 75-87.

Fenson, L., Dale, P.S., Reznick, J.S., Bates, E., Thal, D.J., Pethick, S.J., 1994. Variability in early communicative development. Monographs of the Society for Research in Child Development 59.

Fenson, L., Pethick, S., Renda, C., Cox, J.L., Dale, P.S., Reznick, J.S., 2000. Short-form versions of the MacArthur Communicative Development Inventories. Applied Psycholinguistics 21, 95-115.

Fernald, A., Pinto, J.P., Swingley, D., Weinberg, A., McRoberts, G.W., 1998. Rapid gains in speed of verbal processing by infants in the 2nd year. Psychological Science 9, 228-231.

Fernald, A., Swingley, D., Pinto, J., 2001. When half a word is enough: infants can recognize spoken words using partial phonetic information. Child Development 72, 1003-1015.

Fernald, A., Perfors, A., Marchman, V.A., 2006. Picking up speed in understanding: speech processing efficiency and vocabulary growth across the second year. Developmental Psychology 42, 98-116.

Fisher, C., Tokura, H., 1995. The given-new contract in speech to infants. Journal of Memory and Language 34, 287-310.

Fletcher, C.R., 1984. Markedness and topic continuity in discourse processing. Journal of Verbal Learning and Verbal Behavior 23, 487-493.

Fowler, C.A., Housum, J., 1987. Talkers' signaling of "new" and "old" words in speech and listeners' perception and use of the distinction. Journal of Memory and Language 26, 489-504.

Francis, W.N., Kucera, H., 1982. Frequency Analysis of English Usage: Lexicon and Grammar. Houghton Mifflin, Boston.

Garnham, A., 2000. Mental Models and the Interpretation of Anaphora. Psychology Press, East Sussex.

Garrod, S.C., Sanford, A.J., 1988. Thematic subjecthood and cognitive constraints on discourse structure. Journal of Pragmatics 12, 519-534.

Garrod, S.C., Sanford, A.J., 1994. Resolving sentences in a discourse context: how discourse representation affects language understanding. In: Gernsbacher, M.A. (Ed.), Handbook of Psycholinguistics. Academic Press, New York, pp. 675-698.

Gelman, S.A., Raman, L., 2003. Preschool children use linguistic form class and pragmatic cues to interpret generics. Child Development 74, 308-325.

Gernsbacher, M.A., 1990. Language Comprehension as Structure Building. Erlbaum, Hillsdale, NJ.

Gernsbacher, M.A., Hargreaves, D.J., 1988. Accessing sentence participants: the advantage of first mention. Journal of Memory and Language 27, 699-717.

Givón, T., 1976. Topic, pronoun, and grammatical agreement. In: Li, C.N. (Ed.), Subject and Topic. Academic Press, New York, pp. 149-188.

Gomme, N.J., Johnson, C.E., 1997. Pronominal reference in 3-year-olds' narratives. In: Clark, E.V. (Ed.), The Proceedings of the Twenty-Eighth Annual Child Language Research Forum. CSLI, Stanford, pp. 123-132.

Gordon, P.C., Hendrick, R., 1997. Intuitive knowledge of linguistic co-reference. Cognition 62, 325-370.

Gordon, P.C., Hendrick, R., 1998. The representation and processing of coreference in discourse. Cognitive Science 22, 389-424.

Gordon, P.C., Grosz, B.J., Gilliom, L.A., 1993. Pronouns, names and the centering of attention in discourse. Cognitive Science $17,311-347$. 
Gordon, P.C., Hendrick, R., Ledoux, K., Yang, C.L., 1999. Processing of reference and the structure of language: an analysis of complex noun phrases. Language and Cognitive Processes 14, 353-379.

Grimshaw, J., Rosen, S.T., 1990. Knowledge and obedience: the developmental status of the binding theory. Linguistic Inquiry 21, 187-222.

Grosz, B.J., Sidner, C.L., 1986. Attention, intentions, and the structure of discourse. Computational Linguistics 12, 175204.

Grosz, B.J., Joshi, A.K., Weinstein, S., 1983. Providing a unified account of definite noun phrases in discourse. In: Proceedings of the 21st Annual Meeting of the Association for Computational Linguistics. Cambridge, MA, pp. 44-50.

Gundel, J.K., Hedberg, N., Zacharski, R., 1993. Cognitive status and the form of referring expressions in discourse. Language 69, 274-307.

Heim, I., 1982. The semantics of definite and indefinite noun phrases. Ph.D. Dissertation, University of Massachusetts, Amherst.

Hickmann, M., Hendriks, H., 1999. Cohesion and anaphora in children's narratives: a comparison of English, French, German, and Mandarin Chinese. Journal of Child Language 26, 419-452.

Hickmann, M., Kail, M., Roland, F., 1995. Cohesive anaphoric relations in French children's narratives as a function of mutual knowledge. First Language 15, 277-300.

Hirschberg, J., Litman, D., 1993. Empirical studies on the disambiguation of cue phrases. Computational Linguistics 19, 501-530.

Hoff, E., 2003. The specificity of environmental influence: socioeconomic status affects early vocabulary development via maternal speech. Child Development 74, 1368-1378.

Iida, M., 1998. Discourse coherence and shifting centers in Japanese texts. In: Walker, M., Joshi, A., Prince, E. (Eds.), Centering Theory in Discourse. Clarendon, Oxford, pp. 161-180.

Jackendoff, R., 1990. Semantic Structures. MIT Press, Cambridge, MA.

Järvikivi, J., van Gompel, R.P.G., Hyönä, J., Bertram, R., 2005. Ambiguous pronoun resolution: contrasting the firstmention and subject-preference accounts. Psychological Science 16, 260-264.

Jisa, H., 2000. Increasing cohesion in narratives: a developmental study of maintaining and reintroducing subjects in French. Linguistics 38, 591-620.

Johnson-Laird, P.N., 1983. Mental Models: Towards a Cognitive Science of Language, Inference, and Consciousness. Cambridge University Press, Cambridge.

Kail, R., 1992. Processing speed, speech rate, and memory. Developmental Psychology 28, 899-904.

Kamp, H., Reyle, U., 1993. From Discourse to Logic. Kluwer, Dordrecht.

Karmiloff-Smith, A., 1981. The grammatical marking of thematic structure in the development of language production. In: Deutsch, W. (Ed.), The Child Construction of Language. Academic Press, New York, pp. 121-147.

Kieras, D.E., 1980. Initial mention as a signal to thematic content in technical passages. Memory and Cognition 4, 345-353.

Kintsch, W., 1988. The role of knowledge in discourse comprehension: a construction-integration model. Psychological Review 65, 163-182.

Levy, E.T., 1982. Towards an objective definition of "Discourse Topic". In: Tuite, K., Schneider, R., Chametzky, R. (Eds.), Papers from the Eighteenth Regional Meeting of the Chicago Linguistic Society. CLS, Chicago, pp. $259-304$.

MacWhinney, B., 1977. Starting points. Language 53, 152-168.

MacWhinney, B., Bates, E., 1978. Sentential devices for conveying givenness and newness: a cross-cultural developmental study. Journal of Verbal Learning and Verbal Behavior 17, 539-558.

Maratsos, M.P., 1976. The Use of Definite and Indefinite Reference in Young Children. Cambridge University Press, Cambridge.

Marslen-Wilson, W., Levy, E., Tyler, L.K., 1982. Producing interpretable discourse: the establishment and maintenance of reference. In: Jarvella, R.J., Klein, W. (Eds.), Speech, Place, and Action. Wiley, New York, pp. 339-378.

Perfetti, C.A., Goldman, S.R., 1974. Thematization and sentence retrieval. Journal of Verbal Learning and Verbal Behavior 13, 70-79.

Prince, E., 1981. Toward a taxonomy of given-new information. In: Cole, P. (Ed.), Radical Pragmatics. Academic Press, New York, pp. 223-256.

Prince, E., 1992. The ZPG letter: subjects, definiteness, and information-status. In: Thompson, S., Mann, W. (Eds.), Discourse Description: Diverse Analyses of a Fund Raising Text. John Benjamins, Philadelphia, pp. $295-325$.

Skarabela, B., Allen, S., 2002. The role of joint attention in argument realization in child Inuktitut. In: Skarabela, B., Fish, S., Do, A.H.J. (Eds.), BUCLD 26: Proceedings of the 26th annual Boston University Conference on Language Development. Cascadilla, Boston, pp. 620-630.

Song, H., 2001 April. Young children's sensitivity to discourse patterns in language comprehension. Poster Presented at the Biennial Meeting of Society for Research in Child Development, Minneapolis, MN. 
Song, H., Fisher, C., 2005. Who's “she”? Discourse structure influences preschoolers' pronoun interpretation. Journal of Memory and Language 52, 29-57.

Swingley, D., Pinto, J., Fernald, A., 1999. Continuous processing in word recognition at 24 months. Cognition 71, $73-108$.

Tanenhaus, M.K., Spivey-Knowlton, M.J., Eberhard, K.M., Sedivy, J.C., 1995. Integration of visual and linguistic information in spoken language comprehension. Science 268, 1632-1634.

Tomasello, M., Barton, M., 1994. Learning words in nonostensive contexts. Developmental Psychology 30, 639-650.

Trueswell, J.C., Sekerina, I., Hill, N.M., Logrip, M.L., 1999. The kindergartenpath effect: studying on-line sentence processing in young children. Cognition 73, 89-134.

Tyler, L.K., 1983. The development of discourse mapping processes: the on-line interpretation of anaphoric expressions. Cognition 13, 309-341.

Tyler, L.K., 1984. Integration of information during language comprehension: a developmental study. Papers and Reports on Child Language Development 23, 125-133.

Tyler, L.K., Marslen-Wilson, W.D., 1981. Children's processing of spoken language. Journal of Verbal Learning and Verbal Behavior 20, 400-416.

Walker, M., Joshi, A., Prince, E., 1998. Centering in naturally occurring discourse: an overview. In: Walker, M., Joshi, A., Prince, E. (Eds.), Centering Theory in Discourse. Oxford University Press, New York, pp. 1-28.

Wittek, A., Tomasello, M., 2005. Young children's sensitivity to listener knowledge and perceptual context in choosing referring expressions. Applied Psycholinguistics 26, 541-558.

Wykes, T., 1983. The role of inferences in children's comprehension of pronouns. Journal of Experimental Child Psychology 35, 180-193.

Zangl, R., Klarman, L., Thal, D., Fernald, A., Bates, E., 2005. Dynamics of word comprehension in infancy: developments in timing, accuracy, and resistance to acoustic degradation. Journal of Cognition and Development 6, 179-208. 